\title{
•. THE ELECTROCARDIOGRAM IN PULMONARY EMBOLISM
}

\author{
BY \\ ROBERT H. CUTFORTH AND SAMUEL ORAM
}

From King's College Hospital

Received May 9, 1957

The importance of the electrocardiogram in the diagnosis of pulmonary embolism was first demonstrated by McGinn and White (1935) but general opinion still varies concerning the precise diagnostic value of this method of investigation. As recently as 1952 Newman stated that in only 10-20 per cent of cases of pulmonary embolism is there a characteristic pattern and that electrocardiographic examination is not a good method of making the diagnosis. By contrast, Phillips and Levine (1950) are of the opinion that the diagnosis of pulmonary embolism can be made with a high degree of accuracy and, indeed, that the first clue to the diagnosis may often be found by this method.

The object of this paper is to analyse in detail the electrocardiograms of 50 undoubted cases of pulmonary embolism and to compare these results with those of other workers in order to assess its value in making the diagnosis. In addition, an attempt is made to correlate the severity of the clinical picture with the electrocardiogram, and also to show how the presence or absence of pulmonary infarction affects it.

\section{Material and Method of Selection}

The material was obtained from the records of four hospitals. About a quarter of the cases were seen personally by one of us within 24 hours of the time at which the embolism occurred. All patients had at least one 12-lead electrocardiogram (the three standard leads, the three unipolar limb leads, and six chest leads, V1-6) taken after the embolism and in 25 instances serial records were obtained.

In a study of this kind there are two practical difficulties in obtaining suitable material. The first is to obtain records from patients in whom there is no doubt whatsoever concerning the certainty of the diagnosis. This is discussed below and our diagnostic criteria are given. The second difficulty is that those patients who die very soon after the onset of the embolism frequently do so before there is time for an electrocardiogram to be taken. In this series of 50 patients there are 11 in whom the diagnosis was verified after death. The post-mortem examinations revealed that the coronary arteries were patent in all except Case 43, and this case is discussed separately.

Details of the 11 cases that came to autopsy can be seen in Table I.

In addition to the autopsied cases we studied 83 other patients in whom a clinical diagnosis of pulmonary embolism had been made but we discarded 44 of these because, in our opinion, the clinical picture was not certain enough to put the diagnosis beyond all doubt. The remaining 39 patients were considered by us to be undoubted examples of pulmonary embolism, our criteria being as follows.

Twenty-one suffered a sudden attack of pleuritic pain followed in a few days by hæmoptysis. This attack occurred either within 14 days of a surgical operation or in the presence of a recent venous thrombosis. In none of them did we find any cause other than pulmonary embolism that could explain the clinical picture. In addition, every patient in this group had either 
TABLE I

Summary of Findings in Patients at Necropsy

\begin{tabular}{|c|c|c|c|c|c|c|c|c|}
\hline \multirow{2}{*}{$\begin{array}{l}\text { Case } \\
\text { No. }\end{array}$} & \multirow{2}{*}{ Clinical findings } & \multirow{2}{*}{ Post-mortem findings } & \multirow{2}{*}{$\begin{array}{l}\text { Sur- } \\
\text { vival }\end{array}$} & \multirow{2}{*}{$\begin{array}{l}\text { Time } \\
\text { of EC. }\end{array}$} & \multicolumn{4}{|c|}{ EC. findings } \\
\hline & & & & & RBBB & S1 Q3 T3 & $\mathrm{RVT}^{*}$ & Other \\
\hline 40 & $\begin{array}{l}\text { F. 67. Sudden syncope } \\
\text { and fall in B.P. JVP+ }\end{array}$ & $\begin{array}{l}\text { R.L.L. infarct. Con- } \\
\text { gestive failure. Fe- } \\
\text { moral thrombosis. }\end{array}$ & $\begin{array}{c}13 \\
\text { days }\end{array}$ & $\begin{array}{c}12 \\
\text { hours }\end{array}$ & RBBB & - & - & - \\
\hline 41 & $\begin{array}{l}\text { M. 50. Post-operative. } \\
\text { Sudden syncope and } \\
\text { fall in B.P. }\end{array}$ & $\begin{array}{l}\text { Main P.A. blocked } \\
\text { and multiple small } \\
\text { pulm. emboli. }\end{array}$ & $\begin{array}{c}1 \\
\text { day }\end{array}$ & $\begin{array}{c}8 \\
\text { hours }\end{array}$ & - & S1 Q3 T3 & $\mathbf{R V T} \downarrow$ & $\begin{array}{l}\text { S-T } \\
\text { depr. }\end{array}$ \\
\hline 42 & $\begin{array}{l}\text { M. 54. Chronic cor } \\
\text { pulmonale. Sudden } \\
\text { syncope and fall in } \\
\text { B.P. }\end{array}$ & $\begin{array}{l}\text { Massive infarction R. } \\
\text { lung. Multiple in- } \\
\text { farcts L. lung. Em- } \\
\text { bolus in R.P.A. }\end{array}$ & $\begin{array}{c}5 \\
\text { days }\end{array}$ & $\stackrel{2}{\text { days }}$ & RBBB & S1 Q3 T3 & - & - \\
\hline 43 & $\begin{array}{l}\text { M. 66. Myocardial in- } \\
\text { farct } 2 \text { years previ- } \\
\text { ously. Pleural pain } \\
\text { and hæmoptysis one } \\
\text { week. Sudden syncope. }\end{array}$ & $\begin{array}{l}\text { Cardiac infarcts, old } \\
\text { and recent. Multi- } \\
\text { ple recent pulmon- } \\
\text { ary infarcts. Em- } \\
\text { boli in both P.A. }\end{array}$ & $\begin{array}{c}4 \\
\text { days }\end{array}$ & $\begin{array}{c}2 \\
\text { days } \\
\text { and } 3 \\
\text { days }\end{array}$ & $\begin{array}{c}- \\
\text { RBBB }\end{array}$ & $\begin{array}{c}\text { S1 Q3 T3 } \\
-\end{array}$ & - & $\begin{array}{c}\text { Arrhy- } \\
\text { thmia }\end{array}$ \\
\hline 44 & $\begin{array}{l}\text { F. 58. Post-operative. } \\
\text { Sudden syncope and } \\
\text { fall in B.P. }\end{array}$ & $\begin{array}{l}\text { Carcinoma sigmoid } \\
\text { colon and pelvic } \\
\text { abscess. Two ab- } \\
\text { scesses in L.U.L. } \\
\text { Organizing embolus } \\
\text { in artery to L.U.L. }\end{array}$ & $\begin{array}{c}23 \\
\text { days }\end{array}$ & $\begin{array}{c}5 \\
\text { days } \\
14 \\
\text { days } \\
21 \\
\text { days }\end{array}$ & $\begin{array}{l}- \\
-\end{array}$ & $\begin{array}{l}\overline{\mathrm{T} 3} \\
\mathrm{~T} 3\end{array}$ & $\begin{array}{l}\text { RVT } \downarrow \\
\text { RVT } \downarrow \\
\text { RVT } \downarrow\end{array}$ & $\begin{array}{l}- \\
-\end{array}$ \\
\hline 45 & $\begin{array}{l}\text { F. 68. After pneumo- } \\
\text { nia. Sudden syncope, } \\
\text { fall in B.P., JVP++. }\end{array}$ & $\begin{array}{l}\text { Bilat. bronchopneu- } \\
\text { monia. Embolus } \\
\text { impacted in R. and } \\
\text { L.P.A. }\end{array}$ & $\begin{array}{c}1 \\
\text { hour } \\
30 \\
\text { min. }\end{array}$ & $\begin{array}{c}1 \\
\text { hour } \\
20 \\
\text { min. }\end{array}$ & RBBB & - & $\mathbf{R V T} \downarrow$ & - \\
\hline 46 & $\begin{array}{l}\text { M. 52. Post-operative. } \\
\text { Sudden dyspnœa. No } \\
\text { pain. JVP+. Triple } \\
\text { rhythm. }\end{array}$ & $\begin{array}{l}\text { Bilat. saphenous vein } \\
\text { thrombosis. Coiled } \\
\text { clot in the L.P.A. }\end{array}$ & $\begin{array}{c}2 \\
\text { days }\end{array}$ & $\begin{array}{c}12 \\
\text { hours }\end{array}$ & RBBB & S1 Q3 T3 & RVT $\downarrow$ & - \\
\hline 47 & $\begin{array}{l}\text { F. } 84 . \text { Diabetic pre- } \\
\text { coma. Sudden dys- } \\
\text { pnœa and fall in B.P. }\end{array}$ & $\begin{array}{l}\text { Multiple pulmonary } \\
\text { emboli and throm- } \\
\text { bosis of both P.A. }\end{array}$ & $\begin{array}{c}10 \\
\text { days }\end{array}$ & $\begin{array}{c}3 \\
\text { days }\end{array}$ & - & S1 T3 & $\mathbf{R V T} \downarrow$ & \\
\hline 48 & $\begin{array}{l}\text { F. } 74 . \text { Venous throm- } \\
\text { bosis R. leg } 14 \text { days } \\
\text { previously. Sudden } \\
\text { dyspnoea and JVF+. } \\
8 \text { days later sudden } \\
\text { syncope. }\end{array}$ & $\begin{array}{l}\text { Embolus blocking bi- } \\
\text { furcation of P.A. R. } \\
\text { ext. iliac thrombo- } \\
\text { phlebitis. }\end{array}$ & $\begin{array}{c}13 \\
\text { days }\end{array}$ & $\begin{array}{c}1 \\
\text { day } \\
6 \\
\text { days }\end{array}$ & - & $\begin{array}{l}\text { S1 T3 } \\
\text { Less }\end{array}$ & - & $\begin{array}{l}\text { S-T } \\
\text { depr. } \\
\text { Less }\end{array}$ \\
\hline 49 & $\begin{array}{l}\text { M. 51. Fract. fibula in } \\
\text { plaster } 23 \text { days pre- } \\
\text { viously. Sudden syn- } \\
\text { cope, fall in B.P., } \\
\text { triple rhythm. JVP+. }\end{array}$ & $\begin{array}{l}\text { Embolus blocking } \\
\text { main P.A. }\end{array}$ & $\begin{array}{c}1 \\
\text { day }\end{array}$ & $\begin{array}{c}6 \\
\text { hours }\end{array}$ & RBBB & S1 Q3 T3 & - & - \\
\hline 50 & $\begin{array}{l}\text { F. } 75 \text {. Sudden dyspnoea } \\
2 \text { weeks before admis- } \\
\text { sion. Triple rhythm. } \\
\text { JVP+. }\end{array}$ & $\begin{array}{l}\text { Firmly adherent em- } \\
\text { bolus in R.P.A. }\end{array}$ & $\begin{array}{c}22 \\
\text { days }\end{array}$ & $\begin{array}{c}21 \\
\text { days }\end{array}$ & RBBB & S1 T3 & - & - \\
\hline
\end{tabular}

* = Right ventricular $\mathrm{T}$ wave inversion. 
abnormal physical signs in the chest or X-ray findings supporting the diagnosis of pulmonary infarction (Short, 1951).

Of the remaining 18, the pulmonary embolism occurred within 14 days of a surgical operation in 12 and in the presence of venous thrombosis in the legs in the other 6 patients. Cases 23 to 28 suffered sudden attacks of pleuritic pain and were later found to have physical signs or an $X$-ray appearance suggestive of pulmonary infarction. Cases $29,30,31,32,35$, and 39 suffered attacks of syncope and were later found to have physical signs or X-ray signs suggestive of pulmonary infarction. Cases 22 and 23 complained of a sudden gripping pain in the chest which was later followed by hæmoptysis. Case 34 had a sudden attack of syncope which was later followed by hæmoptysis. Cases 36 and 37 had sudden attacks of syncope with a fall in blood pressure and elevation of the jugular venous pressure. Case 38 complained of a gripping pain in the chest which was rapidly followed by syncope with a fall in blood pressure.

Sex Distribution. The sex distribution was equal in this series, 25 men and 25 women.

Age Incidence. The age distribution in 10-year periods was $15-24,1 ; 25-34,3 ; 35-44$, 4; $45-54,10 ; 55-64,14 ; 65-74,16 ; 75-84,2$. Although the average age was about 60 years or slightly older, the statement that pulmonary embolism is rare under 40 is not borne out, as seven were so.

Clinical Severity of the Cases. It is well recognized that while some patients with pulmonary embolism may suffer severe disturbances of the circulation, giving rise to the classic picture of acute cor pulmonale as described by White (1935), commonly associated with such obvious clinical clues as dyspnœa, cyanosis, pain in the chest, hæmoptysis, and pyrexia, many patients, in fact, do not show these features. Barnes (1937) was the first to point out that the important clinical signs of pulmonay embolism are not cyanosis and dyspnœa but shock, collapse, tachycardia, and a fall in blood pressure.

In order to discover whether there were any differences in the electrocardiographic findings in the two clinical types, we divided our material into two groups according to the clinical findings. Cases were judged to be severe when there was syncope, fall in blood pressure, triple rhythm, elevation of the venous pressure, or any combination of these signs. Twenty-eight patients were so classified, and in the remaining 22 , which we have called the non-severe group, none of these signs was observed.

\section{Electrocardiographic Findings in Pulmonary Embolism}

McGinn and White (1935) described the electrocardiographic changes found in the standard leads in seven cases of acute cor pulmonale resulting from pulmonary embolism. The changes they described were $(a)$ a prominent $\mathrm{S}$ wave and low origin of the T wave in standard lead $\mathrm{I} ;(b)$ the gradual "staircase" ascent of the S-T segment in lead II; and (c) a Q wave and late inversion of $\mathrm{T}$ in lead III. In two cases they also described the changes found in lead IV, a bipolar lead from the front and back of the chest.

Next, Barnes (1937) drew attention to the shift to the right in the electrical axis of the heart, and Durant et al. (1939) showed that transient right bundle-branch block patterns could result from this condition.

Wood (1941) found that the T wave became inverted in lead IVR and in certain other bipolar chest leads following pulmonary embolism, and it soon was clearly established that it is the $T$ wave recorded from those præcordial electrodes facing the right ventricle that may be commonly inverted. This is discussed later.

Since the introduction of the so-called unipolar leads, much attention has been paid by Wilson, Rosenbaum and Johnston (1947), Eliaser and Giansiracusa (1952) and Goldberger (1953) to the alteration of the electrical position of the heart. The commonest finding has been clockwise rotation of the heart about the long axis, and alteration of the electrical axis towards the vertical position is only slightly less common.

The finding of a peaked P wave or "P pulmonale" was discussed by Katz (1946). Wood (1948) found it only occasionally in massive pulmonary embolism while Eliaser and Giansiracusa 
TABLE II

Electrocardiographic Abnormaltities Occurring in Pulmonary Embolism

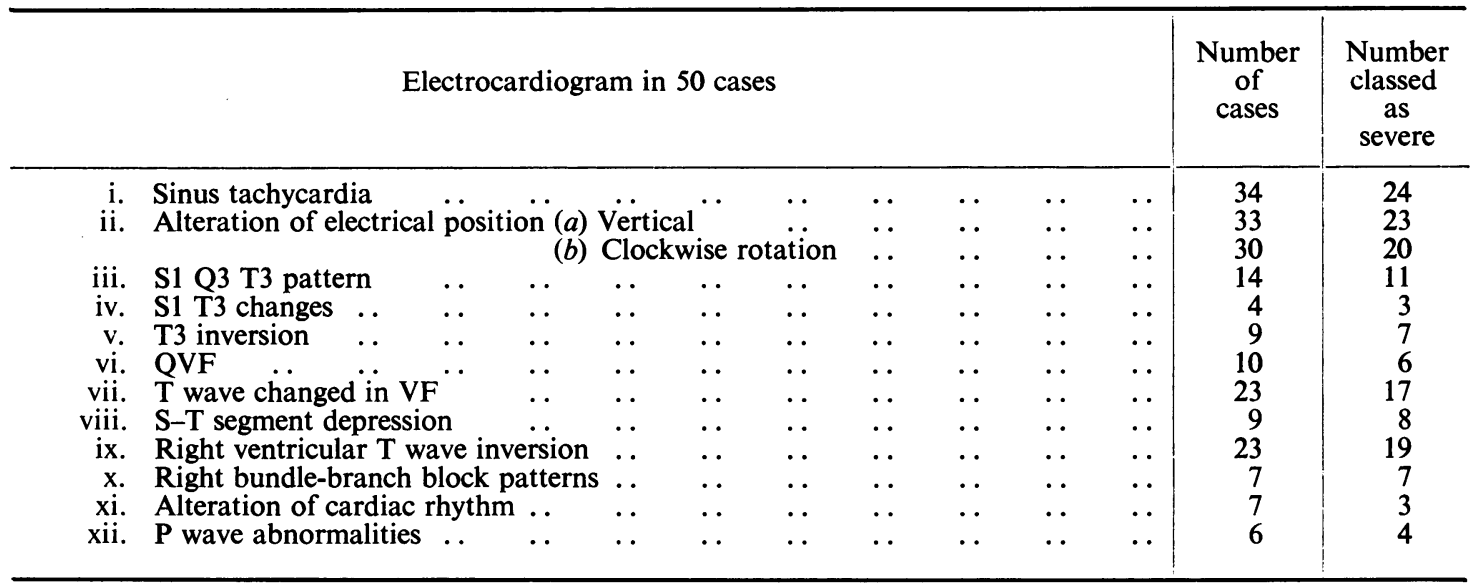

(1952) regard it as a grave prognostic sign. The latter also describe the occurrence of auricular arrhythmias resulting from pulmonary embolism.

The difficulties encountered in distinguishing electrocardiographic patterns found in posterior myocardial infarction from those resulting from pulmonary embolism have been discussed by Barnes (1937), Horn et al. (1939), Sokolow et al. (1940), Phillips and Levine (1950), and Goldberger (1953). This problem is considered below under differential diagnosis.

\section{Analysis of the Electrocardiographic Findings in this Series of Cases}

We have found that there are 12 different electrocardiographic changes that may occur, either singly or in combination, in cases of pulmonary embolism (see Table II). These 12 signs are apt to occur in particular combinations that give rise to 8 recognizable patterns, 3 of which are highly diagnostic.

The 12 changes, their frequency and duration, are as follows:

(i) Sinus Tachycardia. This is recognized as a frequent, if not invariable accompaniment of pulmonary embolism (Fig. 1). The total number of patients showing a tachycardia of 90 a minute or more was 34 . The true figure is undoubtedly higher, however, as several of the electrocardiograms were taken many days after the embolism, and of 22 patients in whom it was taken within 48 hours of the embolism 19 showed a ventricular rate of 90 a minute or more. All these 19 patients were in the severe group. Of the three patients with records taken within 48 hours but not showing tachycardia, Case 46, which was also a severe case, showed a paroxysm of beats at 150 a minute in one lead. In the other two patients (Cases 3 and 6) the electrocardiograms were virtually normal and showed no evidence suggestive of pulmonary embolism. Both these cases were in the non-severe group.

(ii) Alteration of the Electrical Position of the Heart. Both alteration of the electrical axis of the heart towards the vertical position and clockwise rotation of the heart about its long axis as viewed from below have frequently been reported in cases of pulmonary embolism. McGinn and White (1935) noted that none of their cases showed left axis deviation. Kuo and Vander Veer (1950) pointed out that alteration in the electrical axis may be an early and transient phenomenon. Phillips and Levine (1950) mention the importance of clockwise rotation and its value in differential diagnosis, and this point is also stressed by Goldberger (1953).

We have assumed the heart to lie in a vertical position when lead VL shows a $\mathrm{QS}$ or rS pattern, and in a horizontal position when VL shows a $\mathrm{qR}$ or QR pattern (Goldberger, 1953). 


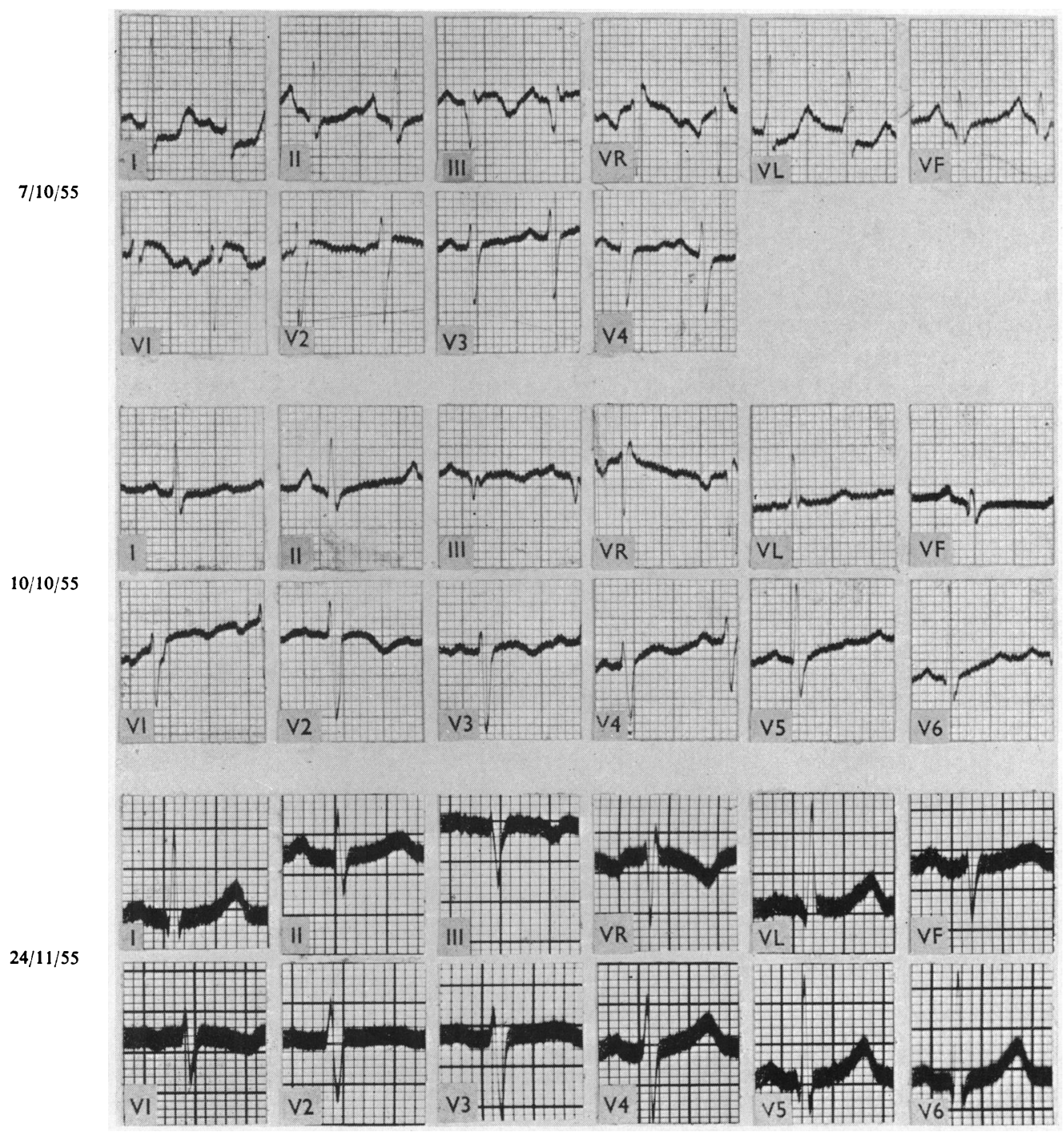

FIG. 1.-Case 35. 7/10/55: Tachycardia (rate 150). Clockwise rotation, $S-T$ segment depression over the left ventricle, an S1 Q3 T3 pattern, right ventricular $\mathrm{T}$ wave inversion, and prominent $\mathbf{P}$ waves. 10/10/55: Disappearance of the $\mathrm{S}-\mathrm{T}$ segment depression, but more obvious right ventricular $T$ wave inversion. 24/11/55: Disappearance of the $S 1$ and the Q3, reversion of the $T$ waves towards normal, a more horizontal position of the heart, and disappearance of the prominent $P$ waves. The $T$ wave in lead III remains inverted.

Of the 50 patients, 33 showed electrocardiographic evidence that the heart was in a vertical position. Consideration of the two groups, severe and non-severe, showed that of the 28 severe cases 23 had hearts in a vertical position: of the 5 patients in this group who did not show this phenomenon, three were suffering from hypertension. In the 22 patients who comprised the nonsevere group, 10 had hearts in a vertical position: of the 12 patients in this group in whom the heart was not vertical, four were suffering from hypertension and one from aortic valve disease.

Duration. Serial electrocardiograms were taken in 18 of the patients with vertical hearts and thus the duration of the vertical position could be ascertained. In five of these the electrical axis 
changed towards the horizontal position as the effects of the embolism wore off. These changes took place in times varying from 5 to 56 days with an average of 33 days (see Fig. 1). In the other 13 patients, the heart remained in a vertical position for an average of 34 days, the range being from 2 to 120 days.

Clockwise rotation of the heart was diagnosed when the transitional zone, as shown by a complex in which the height of the $R$ wave was equal to the depth of $S$, was shifted to the left of the V4 position. It was also diagnosed if a QR, Qr, or qR complex was present to lead VR (Goldberger, 1949). Of the 50 patients 30 showed clockwise rotation; of these 20 were severe cases: 22 patients showed a vertical axis combined with clockwise rotation and of these 16 were severe and 6 non-severe.

Serial electrocardiograms were taken of 15 patients with clockwise rotation. In four of these the rotation disappeared, and in five others the rotation became less, in periods varying from 2 to 120 days with an average of 29 days.

(iii) Abnormalities of S1 Q3 T3; (iv) of S1 T3; and (v) of T3. S1 Q3 T3 changes constitute the classic appearances first described by McGinn and White (1935) but they occurred in only 14 of our patients (see Fig. 1, 2, and 4). Eleven of these were severe and three were not so. In four others the cardiogram showed a conspicuous $S$ wave in lead I and an inverted $T$ wave in lead III, but no $Q$ wave in this lead; three of these were severe. Nine patients, seven of them severe, showed an inverted $\mathrm{T}$ wave in lead III as the only significant finding in the standard leads.

It will be seen, therefore, that inversion of the $\mathrm{T}$ wave in lead III is a frequent finding in cases of pulmonary embolism, and a total of 27 patients showed this change, 21 of them being from the severe group. The exact cause of inversion of the $T$ wave in lead III is difficult to determine. In many cases it is probably a positional phenomenon and in this series, all but 5 of the 27 patients with an inverted $T$ wave in lead III, showed electrocardiographic evidence of a vertical position of the heart together with clockwise rotation. An inverted T wave in lead III, when present as an isolated finding, can have little diagnostic significance, but when combined with other changes it becomes of considerable importance. The relationship of these changes to those found in lead VF is discussed below.

Duration. The first of the S1 Q3 T3 changes to disappear was the deep S wave in lead I. Serial records were taken in 14 patients with this pattern. In 9 of these the S1 had disappeared or become considerably smaller in periods varying from 5 to 42 days with an average of 17 days (see Fig. 1 and 2). In the remaining five cases the follow-up period was not long enough to enable any change to be demonstrated.

The $Q$ wave in lead III is the next of the changes in the standard leads to revert to normal. In 12 patients who had serial records taken, the $\mathrm{Q}$ waves disappeared or became considerably smaller in six, in periods varying from 2 to 48 days with an average of 21 days. In the remaining six the $\mathrm{Q}$ waves persisted, in one for as long as 68 days.

Of all the changes occurring in the standard leads in pulmonary embolism inversion of the $\mathrm{T}$ wave in lead III may be the most persistent. In 17 patients showing this feature of whom serial electrocardiograms were taken, the $T$ wave became upright in three of them after 6,8 , and 16 days, but in the remaining 14 patients the $T$ wave in lead III was still negative after an average of 38 days.

(vi) $Q$ waves in $V F$. Although it has been stated that the absence of a $Q$ wave in lead VF is of help in differentiating the electrocardiogram of pulmonary embolism from that of posterior cardiac infarction, Phillips and Levine (1950) have drawn particular attention to the appearance of a $\mathrm{Q}$ wave in lead VF after pulmonary embolism. We had only one example in which a $\mathrm{Q}$ wave of pathological dimensions occurred (Case 16, see Fig. 2) and in this patient it was present at 36 hours and was deeper eight days later. But in a further nine cases a small $Q$ wave was discernible in lead VF, making a total of 10 , six of which were from the severe group.

Duration. In eight cases in which a $Q$ wave was present in lead VF and serial electrocardiograms were taken, it disappeared in three of them after 2, 15, and 27 days. This change seemed to 
$8 \cdot 9 \cdot 55$
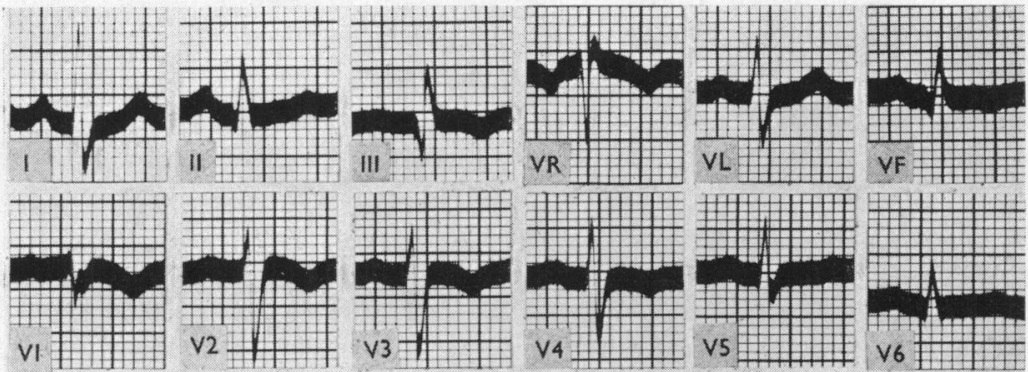

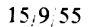
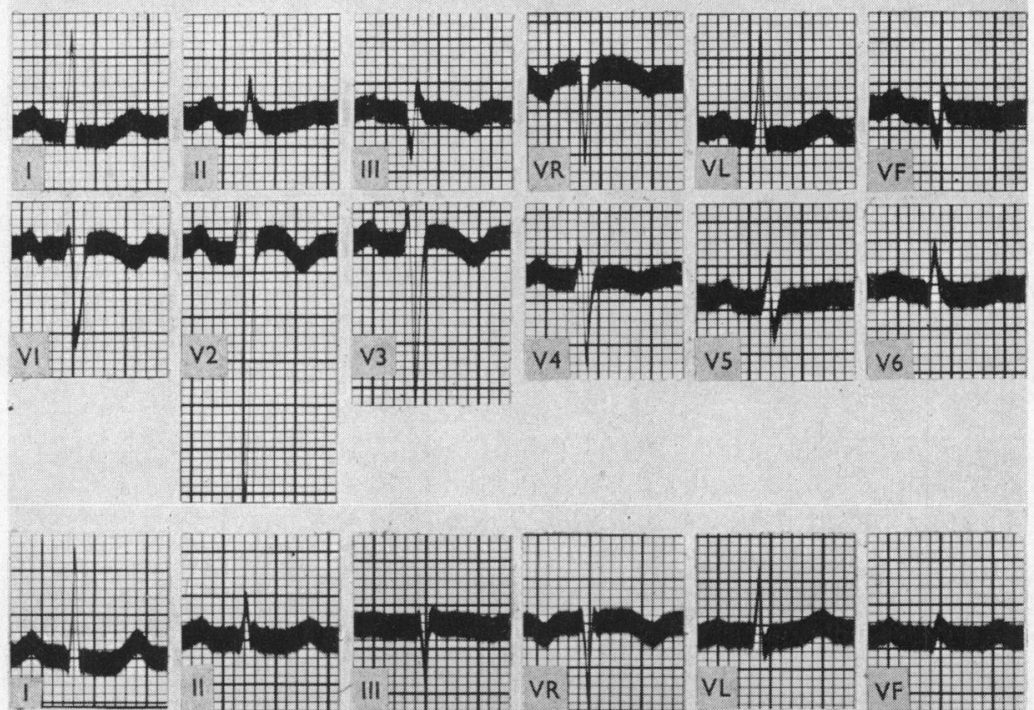

$5: 1055$
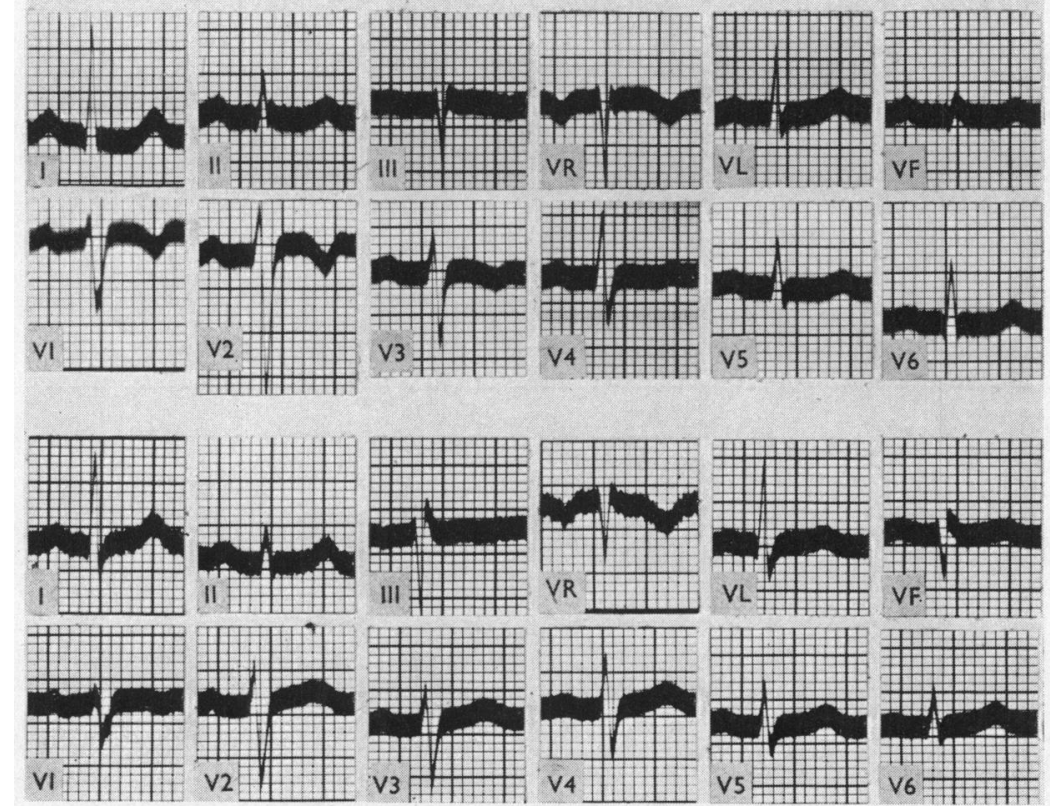

Fig. 2.-Case 16. 8/9/55: An S1 Q3 T3 pattern. A small Q wave and an inverted $T$ wave in lead VF. Right ventricular $T$ wave inversion. 15/9/55: The $S$ wave in leads $I$ and VL has disappeared. The $Q$ wave in lead VF is more prominent and 0.04 sec. wide. 5/10/55: The Q3 has disappeared. The $\mathrm{T}$ waves are now positive in VF and also in V4. 4/11/55: The curves are now normal, only the flat $\mathrm{T}$ wave in lead III remains. 
be associated with the heart taking up a more horizontal position. In the remaining five, one of which was followed up for 69 days, the $Q$ waves persisted unaltered.

(vii) $T$ wave in $V F$. Changes in the $T$ wave in lead VF occurred in 23 patients. In 15 of these the $T$ wave was negative, and in 8 of them it was flat. Seventeen of the 23 cases were in the severe group. All those with a negative $T$ wave in lead VF also showed a negative $T$ wave in lead III. However, in four instances the $T$ wave in lead III was negative while that in lead VF was positive in the initial cardiograms.

Duration. Surprisingly, and in contrast to the persistence of the inversion of the $T$ wave in lead III, the inverted $\mathrm{T}$ wave in lead VF was one of the first signs to disappear. Of 15 patients who had serial electrocardiograms and showed alteration of the $T$ wave in lead VF, 13 showed that the $T$ wave had become positive in an average of 15 days (see Fig. 2 and 3). In the remaining two the $T$ wave changes persisted for 18 and 24 days respectively.

(viii) $S-T$ Segment Depression. Depression of the S-T segment in leads I and II was mentioned as a significant finding in the original paper of McGinn and White (1935). Other authors, among them Murnaghan et al. (1943), Zuckerman et al. (1950), and Laham and Gerbaux (1951) have since pointed out that the S-T segment depression can also appear in lead VL and in those præcordial leads which face the left ventricle. Elevation of the S-T segment sometimes occurs in lead VR and, to a slight extent, in those præcordial leads that face the right ventricle.

In our series, S-T segment depression was seen best in leads I, II, and VL, while S-T elevation was most noticeable in lead VR. We found elevation of the S-T segment in præcordial leads over the right ventricle to be unusual, and it was never of such a degree as to resemble the appearance of an injury current.

Nine of our patients, eight of whom were from the severe group, had electrocardiograms showing S-T segment depression over the left ventricle (Fig. 1 and 4). However, one of them (Case 48) was a man of 74 with a blood pressure of $230 / 120 \mathrm{~mm}$. $\mathrm{Hg}$, and the depression of the S-T segment persisted unchanged for 13 days until his death; we think this depression was due to the effects of hypertension rather than to the pulmonary embolus. In the other eight cases the depression of the S-T segment in left ventricular leads was an early finding (Table III).

Duration. Four of the nine patients died and therefore in these the duration of the depression of the $\mathrm{S}-\mathrm{T}$ segment could not be ascertained. In the remaining five the $\mathrm{S}-\mathrm{T}$ segment depression quickly disappeared, with an average duration of 9 days.

TABLE III

Showing Time of Onset and Disappearance of S-T Segment Depression

\begin{tabular}{|c|c|c|c|c|}
\hline $\begin{array}{l}\text { Case } \\
\text { No. }\end{array}$ & $\begin{array}{c}\text { Time } \\
\text { between } \\
\text { embolism } \\
\text { and } \\
\text { EC. }\end{array}$ & $\begin{array}{l}\text { Leads showing } \\
\mathrm{S}-\mathrm{T} \text { depression }\end{array}$ & $\begin{array}{l}\text { Staircase } \\
\text { ascent }\end{array}$ & Follow-up \\
\hline $\begin{array}{l}45 \\
32\end{array}$ & $\begin{array}{l}1 \text { hour } \\
6 \text { hours }\end{array}$ & $\begin{array}{l}\text { I, II, VL } \\
\text { I, II, VL }\end{array}$ & $\begin{array}{c}\text { Nil } \\
\text { Present }\end{array}$ & $\begin{array}{c}\text { Died } \\
\text { S-T depression gone in } \\
19 \text { days }\end{array}$ \\
\hline 18 & 6 hours & I, II & Present & $\begin{array}{c}\text { S-T depression gone in } \\
2 \text { days }\end{array}$ \\
\hline 35 & 8 hours & I, II, VL & Nil & $\begin{array}{c}\mathrm{S}-\mathrm{T} \text { depression gone in } \\
3 \text { days }\end{array}$ \\
\hline $\begin{array}{l}41 \\
12\end{array}$ & $\begin{array}{l}8 \text { hours } \\
2 \text { days }\end{array}$ & $\begin{array}{l}\text { I, II, VL, V3-V6 } \\
\text { I, II, VL, V4-V6 }\end{array}$ & $\begin{array}{l}\text { Present } \\
\text { Present }\end{array}$ & $\begin{array}{c}\text { Died } \\
\text { S-T depression gone in }\end{array}$ \\
\hline $\begin{array}{l}43 \\
28\end{array}$ & $\begin{array}{l}2 \text { days } \\
3 \text { days }\end{array}$ & $\begin{array}{l}\text { I, II, VL } \\
\text { I, II, VL }\end{array}$ & $\begin{array}{l}\text { Nil } \\
\text { Nil }\end{array}$ & $\begin{array}{c}14 \text { days } \\
\text { Died } \\
\mathrm{S}-\mathrm{T} \text { depression gone in } \\
7 \text { days }\end{array}$ \\
\hline 48 & 13 days & I, II, VL, VF, V4-V6 & Nil & Died \\
\hline
\end{tabular}


$277 / 54$

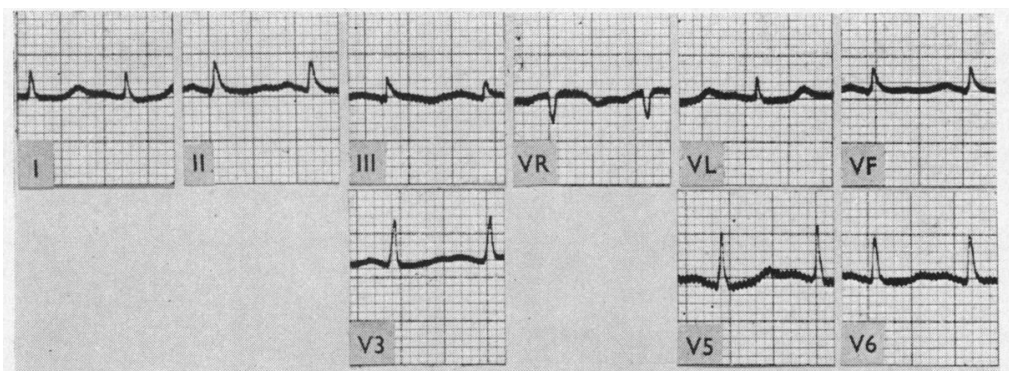

287,54
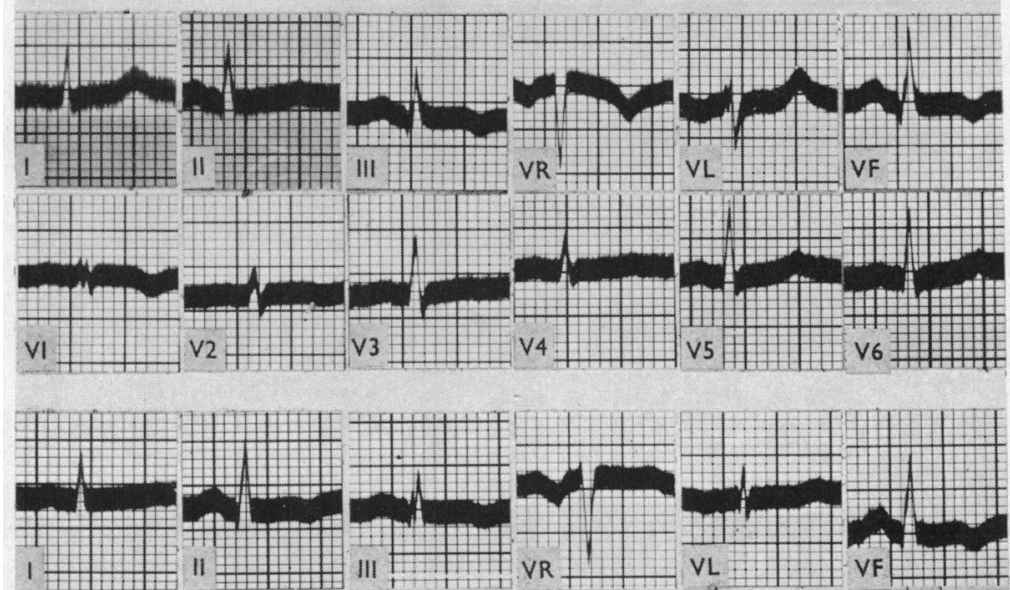

$29 / 7 / 54$

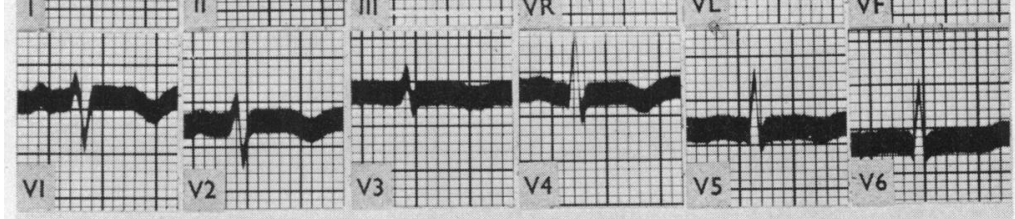

2954

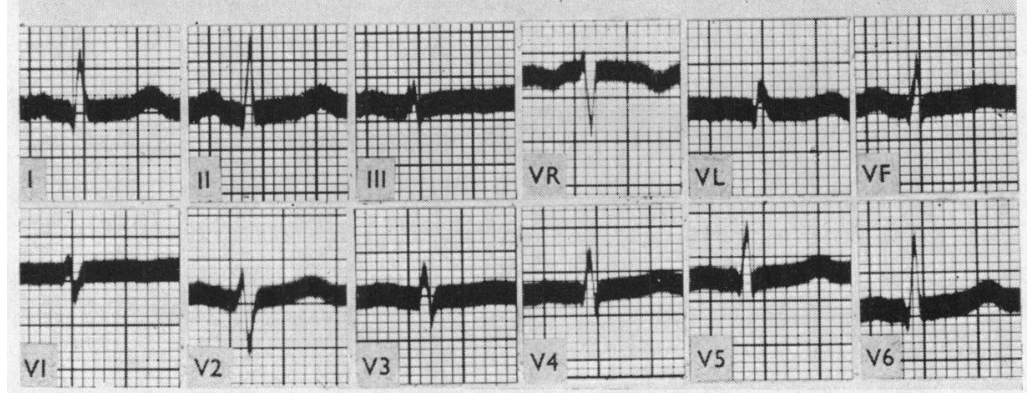

FIG. 3.-Case 38. 27/7/54: Tachycardia, a Q3 T3 pattern and a flat $\mathrm{T}$ wave in VF. 28/7/54: A vertical heart, an S1 Q3 T3 pattern, a small Q wave and an inverted $T$ wave in $V F$, and flat $T$ waves in the right præcordial leads. 29/7/54: Inverted T waves in leads II, III, VF, and V1-V6. 2/9/54: Reversion of the above changes towards normal. 
It is likely that S-T segment depression may be more frequent than our figures suggest since it appears to be an early and transient finding. The gradual "staircase ascent" of the depressed S-T segment in leads I and II described by McGinn and White (1935) does not seem to us to be a very helpful sign, and to decide whether a particular electrocardiogram shows this sign or not is both difficult and unrewarding. Only four of our patients showed this pattern in an easily recognized form (Fig. 4).

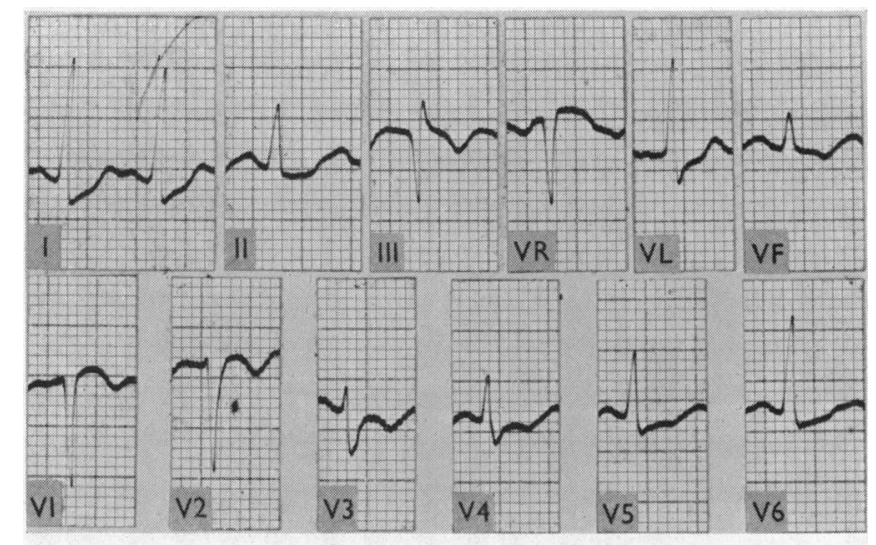

FIG. 4.-Case 41. Showing the "staircase" ascent of the S-T segment, particularly in lead I, also in leads VL, V5, and V6. Also an S1 Q3 T3 pattern, a negative $T$ wave in VF, and right ventricular $\mathrm{T}$ wave inversion.

(ix) Right Ventricular T wave Inversion. Wood (1941) described 10 cases of pulmonary embolism in which leads IVR and bipolar leads from the left chest and right arm and the right chest and right arm were examined. He found that sharp inversion of the $T$ wave occurred without appreciable displacement of the S-T segment. It has since been clearly established by Wood (1948), Myers et al. (1948), Phillips and Levine (1950), Laham and Gerbaux (1951), White (1951), Eliaser and Giansiracusa (1952), and Newman (1952) that in pulmonary embolism the T wave may be inverted in those præcordial leads that face the right ventricle.

In analysing our electrocardiographic findings we have disregarded $\mathrm{T}$ wave inversion in lead $\mathrm{V} 1$ because it is so frequently a normal finding; it may be of significance, however, in those cases in which a record of V1 taken before the embolism is available for comparison.

Of our 50 patients, 23 showed the $\mathrm{T}$ wave to be inverted in those præcordial leads that face the right ventricle (Fig. 1, 2, 3, and 4). Of these 23 cases 19 were severe. It was observed in four patients that the $\mathrm{T}$ wave inversion present in the electrocardiogram taken 24 hours after the embolism was deeper and more extensive two or three days later, though no fresh embolism had occurred (see Fig. 1 and 3). We have found that the $\mathrm{T}$ wave inversion seen in cases of pulmonary embolism may affect leads V1 and V2 only or may spread across the whole præcordial range, well beyond the transitional point, but that the T wave becomes less deeply inverted as the electrode is moved round towards the V6 position.

Duration. Serial electrocardiograms were taken of 13 patients with right ventricular $\mathrm{T}$ wave inversion. In eight of these the $\mathrm{T}$ wave changes gradually disappeared, starting first in the region of V5 and V6 and spreading towards V1 (Fig. 1, 2, and 3). The time taken for the abnormalities to disappear varied from 16 to 120 days with an average of 41 days. Of the remaining five patients, 'reversion of the $T$ wave towards normal had started in three of them by the 10th, 24th, and 42nd day though it was not complete. The remaining two patients were followed only for 16 and 18 days and no changes in the T wave took place during this time. 
(x) Right Bundle-Branch Block. Durant et al. (1939) published an account of three cases in which right bundle-branch block was seen to be present during the first hour or two after the embolism and disappeared after about 12 hours. Wood (1948) found transient right bundlebranch block patterns in three of his twenty cases.

Seven of our patients showed right bundle-branch block. It is noteworthy that these seven were not only classed as severe from the clinical point of view but that all of them died. Further details of these are shown in Table I (Cases 40, 42, 43, 45, 46, 49, and 50). The electrocardiograms of these patients had all been taken less than two days after the embolism, with the exception of Case 50 where the interval was 21 days. In Case 42 the patient was suffering from chronic cor pulmonale and could possibly have had the bundle-branch block before the embolism took place, but we have no evidence on this point. In Case 43 we know that bundle-branch block was not present in a cardiogram taken five months before the embolism occurred.

Duration. Serial electrocardiograms were obtained in only one patient of this group (Case 43) and in that instance they gave no information about the duration of the bundle-branch block because the changes only became obvious in the second one. The time intervals between the occurrence of the embolism and the taking of the electrocardiogram in our seven cases are as follows: Case 45, 1 hour; Cases 40 and 46, 12 hours; Cases 43 and 49, 24 hours; Case 42, 2 days; and Case 50, 22 days. Durant et al. (1939) were of the opinion that right bundle-branch block changes were an early finding and a transient one, but Case 50 in our series showed right bundle-branch block to be present 22 days after the embolism.

(xi) Alteration in Cardiac Rhythm. Murnaghan et al. (1943) found auricular fibrillation in four and auricular flutter in two out of a total of 92 examples of pulmonary embolism. Fliaser and Giansiracusa (1952) found auricular arrhythmia as a delayed phenomenon in three out of eight cases. Zuckerman et al. (1950) have described the production of auricular arrhythmias and A-V block of various degrees in experiments on dogs. On the other hand Newman (1952) is of the opinion that the sudden onset of sinus rhythm in a patient previously fibrillating is a sign suggesting pulmonary embolism, but we have not encountered such a case.

Seven of our 50 patients showed abnormalities of cardiac rhythm and six different types of rhythm were found.

Case 5 (non-severe) was a man of 68 years with hypertension (blood pressure 170/120 mm. $\mathrm{Hg}$ ). Five days after the embolism the electrocardiogram showed partial heart block with a $\mathrm{P}-\mathrm{R}$ interval of $0.24 \mathrm{sec}$. In Case 9 (non-severe) auricular fibrillation was present 24 hours after the embolism. Two days later another electrocardiogram showed sinus rhythm; a negative T3 and a flat TVF were the only remaining signs suggestive of pulmonary embolism. Case 11 (non-severe) showed auricular premature contractions three days after the embolism, but there was no other electrocardiographic abnormality. Case 15 (non-severe) showed auricular fibrillation two days after the embolism; two days later sinus rhythm was present and there were no other signs of pulmonary embolism on the electrocardiogram. Case 17 (severe) showed auricular flutter with an irregular ventricular response; the rhythm changed to auricular fibrillation at 12 days, back to auricular flutter at 15 days, to fibrillation once more at 21 days, and finally reverted to sinus rhythm 26 days after the embolism: the only other electrocardiographic signs of pulmonary embolism were a tiny $Q$ wave in VF together with a flat $T$ wave in that lead and in lead III. Case 29 (severe) 12 hours after the embolism showed multiple ventricular extrasystoles which had disappeared ten days later. Case 46 (severe) showed right bundle-branch block 12 hours after the embolism: the rate was 85 a minute except in lead V3 where a short bout of rapid beating was recorded, and auricular activity was not discernible in the præcordial leads so the mechanism of the arrhythmia was not obvious. This patient died three days after the embolism.

(xii) Abnormalities of the $P$ Wave. It is considered unusual to find any alteration of the $P$ wave in pulmonary embolism. Wood (1948) found it occasionally in massive pulmonary embolism and Zuckerman et al. (1950) mention right auricular dilatation as a late finding in experimental animals but they had no example in their clinical cases. Laham and Gerbaux (1951) found no P wave 
abnormalities in 57 cases of pulmonary embolism. However, Eliaser and Giansiracusa (1952) found " $P$ pulmonale" as a late manifestation in three out of eight cases.

Seven of our 50 patients showed abnormal $P$ waves but one of these (Case 7) was suffering from mitral stenosis and had the typical wide bifid $P$ waves associated with this condition, leaving six who showed alteration of the $P$ pulmonale type for which no reason other than pulmonary embolism could be found. The typical appearance was seen best in lead II in five of the six cases and four out of the six were severe (Cases 33, 35, 43, and 47).

Case 5 has been mentioned above in the section on alterations of rhythm. In addition to partial heart block and S-T segment depression the electrocardiogram showed tall and spiked $\mathrm{P}$ waves, particularly in lead II. The record was taken five days after a pulmonary embolism.

A record taken nine days after the embolism in Case 22 showed an S1 T3 pattern, a negative $T$ wave in lead VF, and right ventricular $T$ wave inversion: the $P$ waves were tall and spiked in leads II, III, and VF. A second cardiogram was not taken until 120 days later: this showed the $P$ waves to be normal, a negative $T$ wave in lead III being the only remaining abnormality.

Case 33 gave a history suggesting two pulmonary emboli at an interval of one week. In the record taken one day after the second embolism the spiked $P$ waves were seen best in lead II, and Q3 T3 and TVF changes were present. The next record taken 33 days later no longer showed any $P$ wave abnormality.

The electrocardiogram in Case 35 was taken eight hours after the pulmonary embolism: in addition to S1 Q3 T3 changes, S-T segment depression and right ventricular $\mathrm{T}$ wave inversion, the $P$ waves were seen to be tall and spiked in leads II and VF. A second record taken three days after the embolism showed no change in this feature but the electrocardiogram taken 47 days after the embolism showed the $\mathbf{P}$ waves had returned to normal (Fig. 1).

In Case 43 a tracing taken two days after the embolism showed no abnormality of the $P$ waves, but a record taken the next day showed them to be typically tall and spiked and seen best in leads V1 and V2. At autopsy multiple pulmonary emboli were present together with myocardial infarction.

In Case 47 the electrocardiogram taken three days after the embolism showed tall spiked $\mathrm{P}$ waves, best seen in lead II; an S1 T3 pattern with right ventricular T wave inversion was also present. The patient died ten days after the embolism and multiple emboli were found at necropsy.

\section{Patients showing No Electrocardiographic Evidence of Pulmonary Embolism}

In our series of 50 cases only 12 had electrocardiograms that showed nothing diagnostic or even suggestive of pulmonary embolism. The remaining 38 all showed electrocardiographic evidence which confirmed the diagnosis. Murnaghan et al. (1943) give figures indicating that about half their cases showed no electrocardiographic evidence of the diagnosis. Carlotti et al. (1947) found no electrocardiographic evidence of acute cor pulmonale in four-fifths of the cases so examined. Laham and Gerbaux (1951) found no suggestive electrocardiographic changes in 58 per cent of 57 cases.

A comparison of the severe and non-severe groups revealed that only one patient of the 28 in the severe group failed to show electrocardiographic evidence of pulmonary embolism, while on the other hand, 11 out of the 22 in the non-severe group showed no such signs.

The one severe example (Case 31) showing no evidence of pulmonary embolism was a woman of 59 years who had undergone a Wertheim hysterectomy 14 days before the embolism took place. She collapsed whilst at stool and was found to be distressed, dyspnœic, and cyanosed. Thrombosis of the right saphenous vein was discovered, and a little later a pleural rub developed at the base of the right lung. An X-ray of the chest taken the next day showed the appearance of a recent pulmonary infarct in the right lower lobe. The electrocardiogram taken the same day (Fig. 5) showed poor voltage curves but the tracing was not diagnostic or even suggestive of pulmonary embolism. 


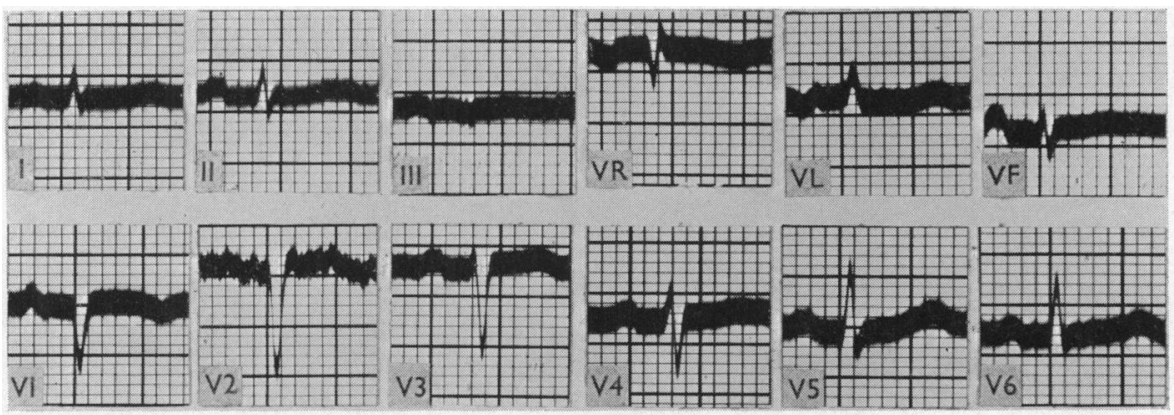

Fig. 5.-Case 31. From a severe case of pulmonary embolism. This tracing was taken two days after the embolism (see text).

\section{Pulmonary Embolism Associated with Myocardial Infarction}

Phillips and Levine (1950) describe a patient (their Case 6) with evidence of old posterior myocardial infarction, who suffered a pulmonary embolism and whose electrocardiogram showed evidence of both conditions. Newman (1952) mentions five cases in which antecedent myocardial infarction distorted the electrocardiographic pattern of pulmonary embolism and made it unrecognizable. Goldberger (1953) states that if pulmonary embolism occurs after myocardial infarction the tracing continues to show only the pattern of the myocardial infarct. In view of the difficulty sometimes encountered at the bedside in differentiating cardiac infarction from pulmonary embolism, the electrocardiographic appearances when both lesions are present are of more than academic importance. In one of our cases, with autopsy confirmation, the cardiographic evidence of the myocardial infarct was completely masked by that of pulmonary embolism and we believe this to be an unusual finding.

A man of 66 (Case 43) was admitted to hospital in 1952 because of anterior myocardial infarction, from which he made a good recovery (Fig. 6, record of 9/3/52). In 1954, during the course of one week he became increasingly short of breath, had a number of hæmoptyses, and was admitted to hospital again. A few hours after his admission he collapsed and became comatose with a pulse rate of 120 a minute, a raised venous pressure, triple rhythm, and diminished breath sounds over the left lower lobe.

On $4 / 7 / 54$, two days after admission to hospital, the standard leads only were recorded at 11.30 a.m. These tracings showed an auricular rate of 200 a minute with a variable ventricular response of about 150 a minute; there was also an S1 Q3 appearance with some elevation of the S-T segment in lead III. The standard leads were recorded again at $9.30 \mathrm{p} . \mathrm{m}$. on the same day and these tracings showed sinus rhythm at a rate of 100 a minute; the elevation of the S-T segment in lead III was no longer obvious and an S1 Q3 T3 pattern had developed. On the following day a 12-lead electrocardiogram was taken and in this tracing the S1 Q3 T3 pattern had disappeared, the $P$ waves were tall and bifid in leads I, V1, and V2, and partial right bundle-branch block was visible in leads V1 and V2; all the T waves were of poor voltage except those in VL which were negative. He died the following day and autopsy showed multiple recent infarcts in the left lower lobe and also in the right lung. There was also evidence of both old and recent myocardial infarction in the lower part of the anterior wall and the apex of the left ventricle.

Comment. The S1 Q3 T3 appearance in the standard leads on 4/7/54 was considered virtually diagnostic of pulmonary embolism. In the record of 5/7/54 the standard leads looked entirely different and apart from the sudden alteration of the shape of the $P$ wave they did not suggest pulmonary embolism; in leads V1 and V2, however, the presence of a partial right bundle-branch block pattern with a QRS interval of $0.12 \mathrm{sec}$. supported this diagnosis. There was no electrocardiographic evidence of recent or old myocardial infarction but the flat or negative $T$ waves over the left ventricle suggested that the myocardium in this situation was not normal. 


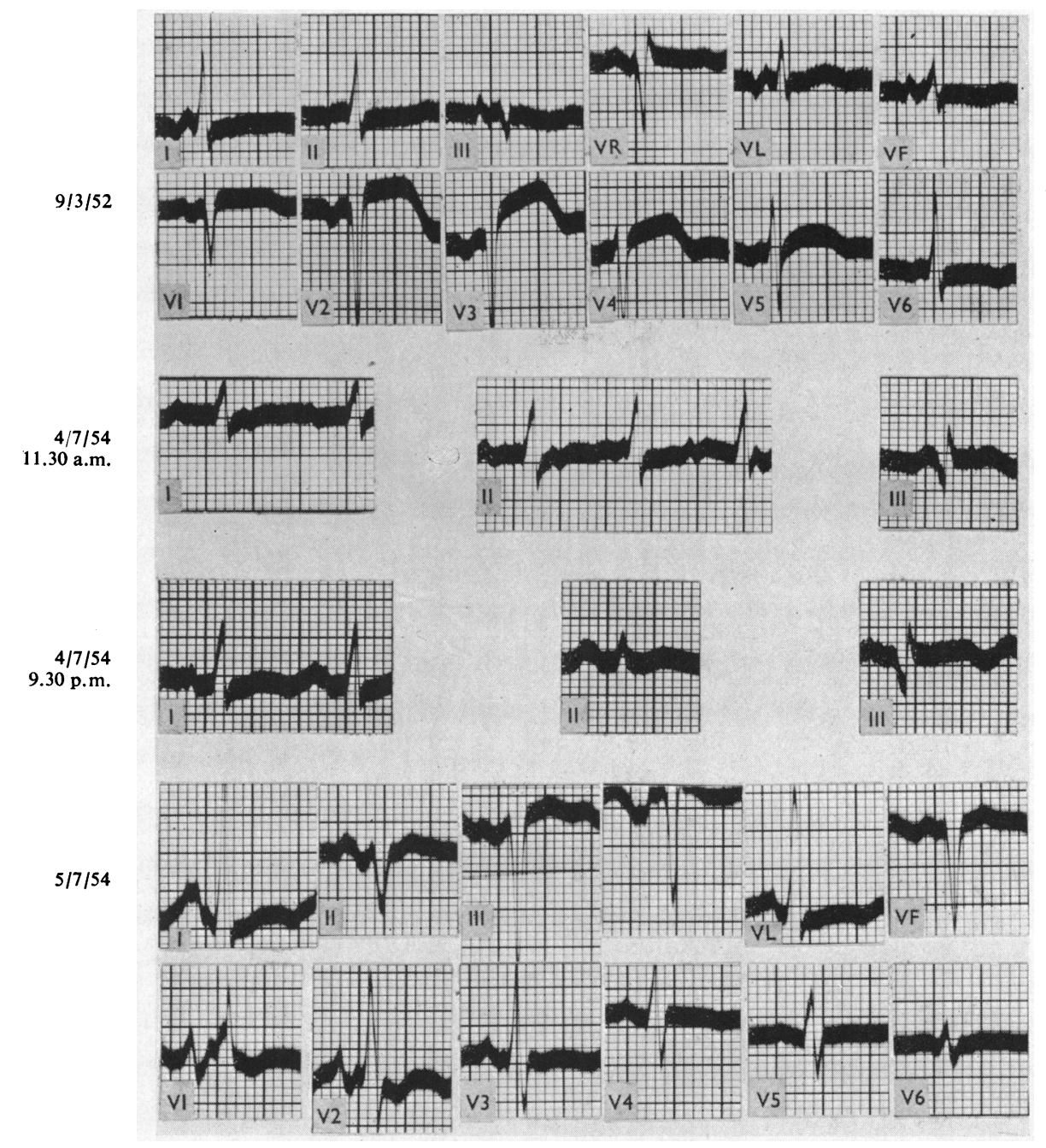

FIG. 6.-Case 43. Pulmonary embolism with myocardial infarction. 9/3/52: The original myocardial infarct. 4/7/54, 11.30 a.m. Auricular tachycardia with an irregular ventricular response. There is also an S1 Q3 pattern. 4/7/54, 9.30 p.m. Sinus rhythm and an S1 Q3 T3 pattern. 5/7/54: Partial right bundle-branch block. Inverted $\mathrm{T}$ waves in leads $\mathrm{I}$ and $\mathrm{VL}$, flat $\mathrm{T}$ waves over the left ventricle.

The electrocardiographic findings in this patient seem to be different from those of previously reported cases, in that evidence of pulmonary embolism is seen whereas that of myocardial infarction is not.

\section{Discussion}

As a result of pulmonary embolism, alteration in the electrocardiogram may occur in the standard leads, the unipolar limb leads, or the chest leads. These changes do not necessarily appear in all leads, nor do they necessarily occur simultaneously. In a suspected case it is important, therefore, always to take a 12-lead electrocardiogram and to repeat the record later if doubt still exists. We would emphasize the value of serial records in difficult cases. In some of our more recent patients 
we recorded leads V3R and V4R to see if they gave any further information, but so far we have not found these leads to be of great value except that sometimes they gave a clearer indication of right bundle-branch block.

Common Diagnostic Patterns. The 12 electrocardiographic changes that we have described may occur separately or combined together in various ways. When they occur alone they may be of little help in diagnosis, but when one compares the various combinations of abnormal patterns with the clinical and autopsy findings, eight recognizable different appearances can be distinguished. We have arranged these patterns in order of their diagnostic reliability (Table IV), and the first three we consider to be diagnostic of pulmonary embolism.

TABLE IV

The Eight Electrocardiographic Patterns commonly found in Pulmonary Embolism, in Order of Diagnostic Reliability *

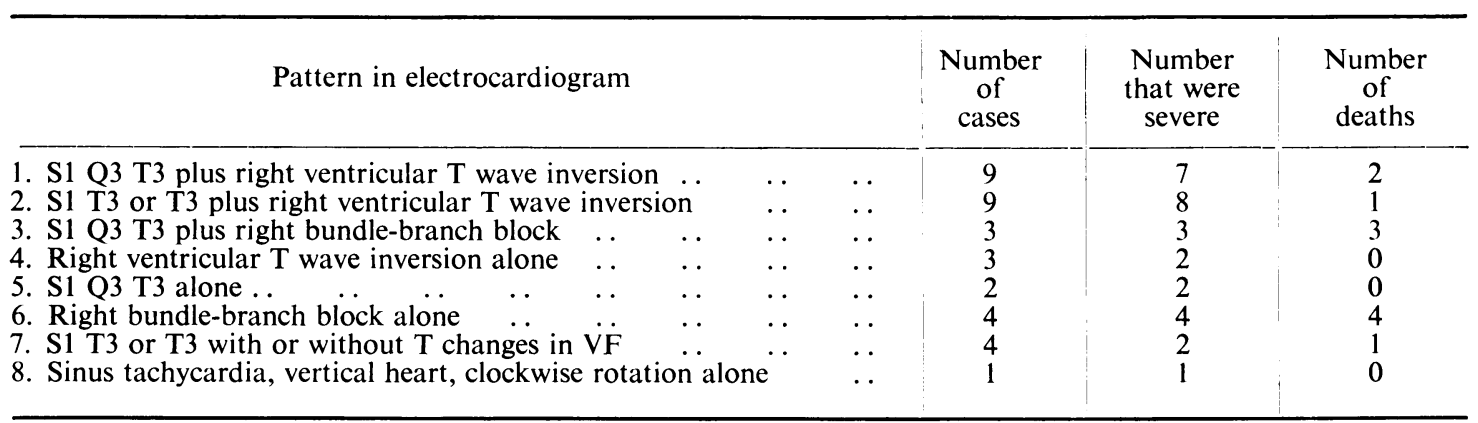

* To any of the above patterns may be added $\mathbf{P}$ pulmonale, depression of the $\mathrm{S}-\mathrm{T}$ segment in leads over the left ventricle, and various arrhythmias (see text).

\section{Patterns Typical of Pulmonary Embolism}

1. S1 Q3 T3 plus Right Ventricular T wave Inversion. This pattern was the most common and also the most reliable indication of pulmonary embolism (Fig. 1, 2, 3, and 4). To the best of our knowledge such a pattern does not occur in any other condition. It was seen in nine cases, seven of which were severe.

2. S1 T3, or T3 Changes, plus Right Ventricular T Wave Inversion. This pattern was equally common, and taken in conjunction with the clinical picture is virtually diagnostic. It occurred in nine cases, eight of which were severe.

3. S1 Q3 T3 plus Right Bundle-Branch Block. Three of the patients with right bundle-branch block also showed an S1 Q3 T3 appearance, all of them were severe cases and died. This combination we also consider to be diagnostic of pulmonary embolism.

\section{Patterns Suggestive of Pulmonary Embolism}

1. Right Ventricular $T$ wave Inversion Alone. This pattern occurred in three cases, two of which were severe. Although the change is not in itself a specific one, we have found it of help in diagnosis since the other conditions giving rise to it are not likely to be confused with pulmonary embolism with the possible exception of antero-septal cardiac infarction. The differences in that condition are discussed below in the section on differential diagnosis.

2. S1 Q3 T3 Pattern Alone. Although this well-known pattern may indicate pulmonary embolism it is not so reliable a diagnostic sign as any of the previous four patterns. It occurred in two patients, both severely ill. At times, posterior cardiac infarction may be accompanied by a deep S wave in lead I, although this is uncommon, but when such a wave is present the appearance may be indistinguishable from that due to pulmonary embolism.

3. Right Bundle-Branch Block Alone. The diagnostic value of this pattern is difficult to assess. 
Right bundle-branch block unaccompanied by any other electrocardiographic evidence of pulmonary embolism was present in four of our cases, all of which were severe. It may occur, of course, in other conditions that give rise to strain on the right ventricle, and for this reason records showing this pattern should be interpreted only in relation to the history and physical signs. Serial tracings may help because other electrocardiographic signs more typical of pulmonary embolism are apt to appear in subsequent records.

4. S1 T3 or T3 Changes Alone. Although this pattern occurs in pulmonary embolism (four cases) it may so frequently be present for other reasons that it cannot be considered of much confirmatory value. Simultaneous inversion of the T wave in lead VF is common to this pattern.

5. Sinus Tachycardia, Clockwise Rotation, Vertical Heart. This pattern was frequent and all three features occurred in 22 of 50 patients, but it was usually combined with other changes, and as an isolated finding occurred in only one patient. By itself it is often a normal finding, but there is one occasion on which it is of help as a diagnostic sign, namely when it appears suddenly in a patient whose previous electrocardiogram showed a different pattern.

To any of the above patterns may be added the typical tall, spiked $\mathrm{P}$ pulmonale, usually best seen in standard lead II, but as mentioned previously this abnormal P wave is often of very short duration and was present in the records of only 6 of 50 patients. Nevertheless, when present it greatly strengthens the diagnosis, particularly if it is a transient finding. Similarly, depression of the S-T segment in leads over the left ventricle may accompany any of the above patterns, and in eight out of nine of the patients showing this sign the illness was severe.

Although alteration of rhythm occurred in seven patients, the various arrhythmias produced are not characteristic of pulmonary embolism.

\section{DifFERENTIAL Diagnosis}

As we have shown, some of the electrocardiographic patterns seen in pulmonary embolism are diagnostic, but some are difficult to distinguish from those seen in other conditions. It should be emphasized that the diagnosis is primarily a clinical matter and that the electrocardiogram should be looked upon as an aid to the history and physical signs. Unlike the high degree of accuracy shown by electrocardiography in the diagnosis of myocardial infarction, in pulmonary embolism one can expect equivocal findings more often than not. Even so, it is our opinion that more assistance can be obtained from electrocardiography in the diagnosis of pulmonary embolism than is currently believed.

The electrocardiogram in chronic cor pulmonale is possibly the most likely to simulate that of pulmonary embolism. It may show right ventricular $\mathrm{T}$ wave inversion and an S1 T3 pattern together with a vertical heart and clockwise rotation. On clinical grounds, however, it is usually easy to distinguish this type of case from pulmonary embolism, but the occurrence of pleuritic pain and hæmoptysis in a patient with chronic bronchitis and emphysema may present a difficult problem, and for that matter such patients, if bedridden, may suffer embolic pulmonary infarction. There are two electrocardiographic points of difference between chronic cor pulmonale and pulmonary embolism. The first is that many cases of pulmonary heart disease show a tall spiked $P$ wave as a permanent feature in the electrocardiogram. Wood (1948) found this in 85 per cent of 100 cases. On the other hand, the finding of these abnormal $P$ waves is rare ( 6 out of 50 of our cases) and also of much shorter duration in pulmonary embolism. The second is the concomitant finding of right ventricular hypertrophy in chronic cor pulmonale; this is not seen in uncomplicated pulmonary embolism.

Antero-septal myocardial infarction is sometimes diagnosed in error when in fact pulmonary embolism is present. In our view this difficulty has not been sufficiently emphasized. In anteroseptal infarction the presence in the præcordial leads of an injury current or of abnormal $Q$ waves will clarify the diagnosis in the majority of cases because neither of these signs occurs in pulmonary embolism. In pulmonary embolism the $\mathrm{T}$ wave inversion is usually deepest in leads V1 and V2, becoming progressively less towards V6, whereas gradual lessening of the inversion of the T wave 
from leads V1 to V5 is not necessarily a feature of anteroseptal infarction. The S1 Q3 T3 pattern found in pulmonary embolism is not a feature of anteroseptal infarction, though clockwise rotation may occur in the latter condition. Serial electrocardiograms will show the two maladies to progress in different ways.

In differentiating posterior myocardial infarction from pulmonary embolism the significance of a $\mathrm{Q}$ wave in association with an inverted $\mathrm{T}$ wave in leads III and VF has been the subject of considerable discussion. Phillips and Levine (1950) illustrated these difficulties with one of their cases and Newman (1952) drew up a list of differences between the electrocardiographic findings in pulmonary embolism and posterior myocardial infarction. In our series we have not encountered much difficulty, and although ten cases showed a $Q$ wave in lead VF, in only one was it of pathological dimensions (Case 16, see Fig. 2). Phillips and Levine (1950) found a conspicuous $\mathrm{Q}$ in VF in two of their eight cases. Their cardiograms were taken a few hours after the embolism whereas some of ours were taken considerably later (Table V). If the heart is in a vertical position and clockwise rotation together with forward rotation of the apex is present, we do not think that the appearance of even a deep $Q$ wave in lead VF is unexpected in pulmonary embolism. In such instances the $Q R$ and downward $T$ in lead VF will be accompanied by an RS in lead VL and a QR in lead VR.

\section{TABLE V}

Time Interval betWeen the Embolism and First Electrocardiogram and the Number of Cases With Positive OR Negative Electrocardiographic Findings

\begin{tabular}{l|c|c}
\hline $\begin{array}{c}\text { Time between } \\
\text { embolism and } \\
\text { first EC. }\end{array}$ & $\begin{array}{c}\text { No. of cases } \\
\text { with positive } \\
\text { findings }\end{array}$ & $\begin{array}{c}\text { No. of cases } \\
\text { with negative } \\
\text { findings }\end{array}$ \\
\hline 12 hours or less & 7 & 0 \\
24 hours & 7 & 2 \\
2 days & 7 & 1 \\
3 days & 4 & 3 \\
4 days & 1 & 0 \\
6 days & 4 & 2 \\
7 days & 3 & 1 \\
More than 7 days & 0 & 3 \\
\hline
\end{tabular}

We find that the most important point in the diagnosis is the presence of an injury current in leads III and VF in many cases of posterior infarction, such an appearance never being found in pulmonary embolism. Also, in uncomplicated posterior infarction the $T$ waves in the præcordial leads may be tall but they are never inverted, whereas in pulmonary embolism the præcordial $\mathrm{T}$ waves may be normal, flat or inverted, but not tall. Goldberger (1953) states that the clockwise rotation of the heart, common in pulmonary embolism, is unusual in posterior infarction unless anterior infarction is also present.

The right ventricular strain pattern from any cause shows $T$ waves indistinguishable from those seen in pulmonary embolism. Transient changes can occur in rheumatic carditis, diphtheria, and pneumonia. Phillips and Levine (1950, their Case 7) described similar appearances due to massive collapse of the lungs, though the $T$ wave inversion was only obvious in lead V1. In normal infants or children the $T$ waves may be inverted in those præcordial leads that face the right ventricle (Zeigler, 1951). Pulmonary embolism occurring in a young child might well present a confusing electrocardiographic appearance, but we have not encountered such a case. Goldberger (1953) published tracings of a normal adult showing right ventricular $\mathrm{T}$ wave inversion with a " juvenile T wave pattern". 


\section{COMPARISON OF SEVERE AND NoN-SEVERE Groups}

In the group of 28 patients that we have called severe, significant electrocardiographic findings were far more frequent than in the non-severe cases. No fewer than 27 of them showed evidence of pulmonary embolism in the electrocardiogram. In the same group there were 19 examples of right ventricular $\mathrm{T}$ wave inversion and 11 examples of the complete McGinn and White (1935) pattern. All seven examples of right bundle-branch block, either alone or accompanied by the S1 Q3 T3 appearance, were also from the severe group.

In the 22 patients belonging to the non-severe group the figures were very different. Only 11 showed any evidence of pulmonary embolism in the electrocardiogram. Among these eleven there were four examples of right ventricular $T$ wave inversion and three of the complete McGinn and White pattern: there were no instances of bundle-branch block (Tables II and VI).

TABLE VI

A Comparison of the Findings in the Severe and Non-SEvere Groups

\begin{tabular}{|c|c|c|c|c|c|c|c|c|c|c|c|}
\hline & & \multicolumn{2}{|c|}{$\begin{array}{l}\text { Electro- } \\
\text { cardiographic } \\
\text { changes }\end{array}$} & \multicolumn{2}{|c|}{$\begin{array}{l}\text { RV T wave } \\
\text { inversion }\end{array}$} & \multicolumn{2}{|c|}{$\begin{array}{c}\text { S1 Q3 T3 } \\
\text { pattern }\end{array}$} & \multicolumn{2}{|c|}{ RBBB } & \multicolumn{2}{|c|}{$\begin{array}{l}\text { Rhythm } \\
\text { alterations }\end{array}$} \\
\hline & & Positive & Negative & Present & Absent & Present & Absent & Present & Absent & Present & Absent \\
\hline $\begin{array}{l}\text { Severe } \\
\text { Non-severe }\end{array}$ & $\begin{array}{l}\ldots \\
\ldots\end{array}$ & $\begin{array}{l}27 \\
11\end{array}$ & $\begin{array}{r}1 \\
11\end{array}$ & $\begin{array}{r}19 \\
4\end{array}$ & $\begin{array}{r}9 \\
18\end{array}$ & $\begin{array}{r}11 \\
3\end{array}$ & $\begin{array}{l}17 \\
19\end{array}$ & $\begin{array}{l}7 \\
-\end{array}$ & $\begin{array}{l}21 \\
22\end{array}$ & $\begin{array}{l}3 \\
4\end{array}$ & $\begin{array}{l}25 \\
18\end{array}$ \\
\hline
\end{tabular}

Of the 22 non-severe cases it was noteworthy that 18 had pleuritic pain followed by hæmoptysis. Such syndromes do not generally present diagnostic difficulties; this is fortunate because in our series electrocardiography yielded no information in one-half of them. It is in the clinically less obvious combinations of sudden dyspnœa, fall in blood pressure, or syncope that electrocardiography may be of considerable value. In them positive electrocardiographic evidence of pulmonary embolism was found in 27 of 28 cases (Table VI).

\section{The Relationship of Pulmonary Infarction to the Electrocardiographic Findings}

Little attention has been paid to the presence or absence of pulmonary infarction in relation to the electrocardiographic pattern in pulmonary embolism. Sokolow et al. (1940) and Laham and Gerbaux (1951) could not demonstrate any correlation. We have found that there is a rough relationship between the presence of pulmonary infarction and the electrocardiographic findings, but the inherent difficulties in deciding upon the presence or absence of pulmonary infarction makes accurate correlation difficult. Of our 11 patients coming to necropsy, five had pulmonary infarction and six did not. In the others we have relied on the $\mathrm{X}$-ray findings described by Short (1951) to indicate pulmonary infarction. X-rays of the chest were taken after the pulmonary embolism in 34 patients and of these 25 showed evidence of pulmonary infarction. Thus of the 45 patients with embolism, 30 showed infarction and 15 did not.

The absence of infarction meant a more serious illness. Of the 15 patients without it 13 belonged to the severe group, whereas of the 30 who had pulmonary infarcts only 14 were severe (Table VII).

\section{ELECTROCARDIOGRAPHIC CORRELATION}

In pulmonary embolism severe disturbance of the circulation with embarrassment of the right ventricular muscle is shown electrocardiographically by right ventricular $T$ wave inversion and right bundle-branch block. In our series these patterns occurred more frequently in the absence of pulmonary infarction than in its presence (Table VII). Newman (1952) states that the severity and magnitude of the pulmonary infarction do not necessarily run parallel with the extent of the 
TABLE VII

A Comparison between Patients with Pulmonary Infarction and those without

Pulmonary infarction ... No pulmonary infarction

\begin{tabular}{|c|c|c|c|c|c|c|c}
\multicolumn{2}{c|}{ Severity } & \multicolumn{2}{c|}{ RBBB } & $\begin{array}{c}\text { RV T wave } \\
\text { inversion }\end{array}$ & \multicolumn{2}{c}{ Deaths } \\
\hline Severe & Non-severe & Present & Absent & Present & Absent & Survived & Died \\
\hline 14 & 16 & 3 & 27 & $\begin{array}{r}11 \\
8\end{array}$ & $\begin{array}{r}19 \\
7\end{array}$ & $\begin{array}{r}25 \\
9\end{array}$ & $\begin{array}{r}5 \\
6\end{array}$ \\
\hline 13 & 2 & 4 & 11 & 8 & & \\
\hline
\end{tabular}

electrocardiographic change and cannot be estimated from it. We agree that the size of the pulmonary infarct cannot be correlated with the electrocardiographic findings, but it is possible that there is a relationship between the size of the embolus and the presence or absence of infarction. It is recognized that large emboli often do not cause pulmonary infarction. It is possible, therefore, that many patients who show no infarction may have had a large embolism. This seems to be borne out by our experience. Thus in our series it is not the size of the infarct that determines cardiographic abnormalities but the grade of the circulatory effects of the embolism. The severity of the case, as defined by us, and the cardiographic changes run very largely parallel (Table VII).

Malinow et al. (1946) working with dogs, and Phillips and Levine (1950) produced evidence showing that small emboli could cause profound effects on the circulation, out of all proportion to their size. Two of our post-mortem examinations (Cases 46 and 50) revealed emboli in only one branch of the pulmonary artery, and in two others (Cases 40 and 44) the embolus was found in branches of the second order.

Animal experiments by Gibbon et al. (1932), however, indicate that more than 50 per cent of the pulmonary circulation must be occluded before a significant fall in systemic blood pressure occurs and this has been confirmed by Love et al. (1938). In man electrocardiograms were recorded during and after pneumonectomy by Barnes (1941) and Semisch and Merves (1942) because it was thought that the sudden occlusion of about one-half of the pulmonary circulation might be reflected in the tracings: Semisch and Merves found surprisingly little electrocardiographic evidence and Barnes found none.

The foregoing facts suggest that there is some process other than simple occlusion by the embolus involved in the production of acute cor pulmonale. The existence of a pulmonary vasoconstrictor reflex has been suggested by Megibow et al. (1942) and by Zuckerman et al. (1950) and this seems to be the most likely explanation, but the mechanism of the reflex has always been obscure. Recently Smith and Smith (1955) have postulated a humoral mechanism with "serotonin" (5 hydroxytryptamine) as the agent. According to Zucker (1953) this substance is released from platelets in the first stage of clot formation, and causes a sharp rise of pressure when it reaches the pulmonary circulation. This hypothesis would provide explanations for many of the apparent anomalies seen in pulmonary embolism. It might explain the very variable duration of some of the electrocardiographic findings and also why a normal electrocardiogram can be found two days after what appeared to be a very severe embolism, as in our Case 31.

\section{SUMMARY}

Ninety-four patients diagnosed as suffering from pulmonary embolism were examined and in 50 of these the diagnosis was considered certain, either as a result of necropsy or by clinical and radiological criteria that we have defined.

Analysis of the electrocardiograms of these 50 patients showed 12 different signs; these are described and their frequency and duration recorded.

When the 12 electrocardiographic signs were considered together, they were seen to fall into 
eight common patterns, the first three of which we consider to be diagnostic of pulmonary embolism, namely: S1 Q3 T3 appearance plus right ventricular $\mathrm{T}$ wave inversion,

$\mathrm{S} 1 \mathrm{~T} 3$ or T3 appearance plus right ventricular $\mathrm{T}$ wave inversion, and

S1 Q3 T3 appearance plus right bundle-branch block.

The remaining five patterns are highly suggestive of the diagnosis when considered in relation to the clinical history.

There was no arrhythmia particularly characteristic of pulmonary embolism. The much quoted "staircase ascent" of the S-T segment was in our experience of little diagnostic value. A tall spiked $P$ wave was found in six cases out of 50 , four of which were severe.

The electrocardiographic findings have been correlated with the clinical severity of the cases, 28 of which were classed as severe and 22 as not severe. The findings in embolism with pulmonary infarction are compared with those in embolism without pulmonary infarction. The latter group showed electrocardiographic signs more frequently than the former.

The differential diagnosis is discussed.

Details are given of an example of pulmonary embolism occurring at the same time as myocardial infarction, the cardiograms showing signs of pulmonary embolism, but not of cardiac infarct.

It is our opinion that more assistance can be obtained from electrocardiography in the diagnosis of pulmonary embolism than is commonly believed. Of the 50 cases, 38 showed cardiographic evidence of pulmonary embolism and these signs sometimes persisted for more than two months. It is particularly in the clinically less obvious illnesses with dyspnœa, and fall in blood pressure or syncope that it can help, and 27 of 28 such cases showed electrocardiographic evidence of pulmonary embolism.

\section{REFERENCES}

Barnes, A. R. (1937). J. Amer. med. Ass., 109, 1347.

Barnes, C. (1941). Proc. roy. Soc. Med., 34, 606.

Carlotti, J., Hardy, I. B., Linton, R. R., and White, P. D. (1947). J. Amer. med. Ass., 134, 1447.

Durant, T. M., Ginsberg, I. W., and Roesler, H. (1939). Amer. Heart J., 17, 423.

Eliaser, M., and Giansiracusa, F. (1952). Amer. Heart J., 43, 533.

Gibbon, J. H., Hopkinson, M., and Churchill, E. D. (1932). J. clin. Invest., 11, 543.

Goldberger, E. (1949). Amer. J. Med., 7, 756.

(1953). Unipolar Lead Electrocardiography and Vectorcardiography. 3rd ed. London.

Horn, H., Dack, S., and Friedberg, C. K. (1939). Arch. intern. Med., 64, 296.

Katz, L. N. (1946). Electrocardiography. 2nd ed. Philadelphia.

Kuo, P. T., and Vander Veer, J. B. (1950). Amer. Heart J., 40, 825.

Laham, J., and Gerbaux, A. (1951). Arch. Mal. Coeur, 44, 328.

Love, W. S., Brugler, G. W., and Winslow, N. (1938). Ann. intern. Med., 11, 2109.

Malinow, M. R., Katz, L. N., and Kondo, B. (1946). Amer. Heart J., 31, 702.

McGinn, S., and White, P. D. (1935). J. Amer. med. Ass., 104, 1473.

Megibow, R. S., Katz, L. N., and Steinitz, F. S. (1942). Surgery, 11, 19.

Murnaghan, D., McGinn, S., and White, P. D. (1943). Amer. Heart J., 25, 573.

Myers, G. B., Klein, H. A., and Stoffer, B. E. (1948). Amer. Heart J., 35, 1.

Newman, D. A. (1952). J. Fla. med. Ass., 38, 701.

Phillips, E., and Levine, H. D. (1950). Amer. Heart J., 39, 205.

Semisch, C. W., and Merves, L. (1942). Arch. intern. Med., 69, 417.

Short, D. S. (1951). Quart. J. Med. N.S., 20, 233.

Smith, G., and Smith, A. N. (1955). Surg. Gynec. Obstet., 101, 691.

Sokolow, M., Katz, L. N., and Muscovitz, A. N. (1940). Amer. Heart J., 19, 166.

White, P. D. (1935). Ann. intern. Med., 9, 115.

(1951). Heart Disease. 4th ed. New York.

Wilson, F. N., Rosenbaum, F. F., and Johnston, F. D. (1947). Advanc. intern. Med., $2,1$.

Wood, P. (1941). Brit. Heart J., 3, 21.

(1948). Brit. Heart J., 10,87.

Zeigler, R. F. (1951). Circulation (N.Y.), 3, 438.

Zucker, M. B. (1953). Abstracts of Communications: Nineteenth International Physiological Congress, p. 915.

Zuckerman, R., Rodriguez, M. I., Sodi Pallares, D., and Bisteni, A. (1950). Amer. Heart J., 40, 805. 